\section{Histochemical detection of ace- togenins and storage molecules in the endosperm of Annona macroprophyllata Donn Sm. seeds}

\author{
G. Laguna Hernández, ${ }^{1}$ \\ A.E. Brechú Franco, ${ }^{1}$ \\ I. De-la-Cruz-Chacón, ${ }^{2}$ \\ A.R. González-Esquinca ${ }^{2}$
}

'Faculty of Sciences, National

Autonomous University of Mexico,

Coyoacán, Mexico

${ }^{2}$ Institute of Biological Sciences,

University of Sciences and Arts

of Chiapas, Tuxtla Gtz., Chiapas, Mexico

\section{Abstract}

Acetogenins (ACGs) are bioactive compounds with cytotoxic properties in different cell lines. They are antitumoural, antiparasitic, antimalarial, insecticidal, antimicrobial, antifungal and antibacterial. These secondary metabolites function in plant defence and are found in specific organelles and specific cells, thereby preventing toxicity to the plant itself and permitting site-specific defence. The aim of this work was to histochemically determine the in situ localisation of ACGs in the endosperm of Annona macroprophyllata seeds using Kedde's reagent. Additionally, the colocalisation of ACGs with other storage molecules was analysed. The seeds were analysed after 6 and 10 days of imbibition, when 1 or 2 $\mathrm{cm}$ of the radicle had emerged and metabolism was fully established. The seeds were then transversally cut in half at the midline and processed using different histological and histochemical techniques. Positive reactions with Kedde's reagent were only observed in fresh, unfixed sections that were preserved in water, and staining was found only in the large cells (the idioblasts) at the periphery of the endosperm. The ACGs' positive reaction with Sudan III corroborated their lipid nature. Paraffin sections stained with Naphthol Blue Black showed reactions in the endosperm parenchyma cells and stained the proteoplasts blue, indicating that they might correspond to storage sites for albumin-like proteins. Lugol's iodine, which is similar in chemical composition to Wagner's reagent, caused a golden brown reaction product in the cytoplasm of the idioblasts, which may indicate the presence of alkaloids.

Based on these results, we propose that Kedde's reagent is an appropriate histochemi- cal stain for detecting ACGs in situ in idioblasts and that idioblasts store ACGs and probably alkaloids. ACGs that are located in idioblasts found in restricted, peripheral areas of the endosperm could serve as a barrier that protects the seeds against insects and pathogen attack.

\section{Introduction}

Species in the Annonaceae have endospermic seeds with minute embryos. The ruminate endosperm occupies almost the entire volume of the seed and contains diverse storage molecules, including lipids, albumin-type proteins, and polysaccharides, such as starch and galactomannans. ${ }^{1-5}$ These storage substances are used during embryonic development, germination and seedling establishment, which occurs almost a month after the onset of germination. ${ }^{6}$ The endosperm of the mature seeds also contains secondary metabolites, such as alkaloids, polyphenols, essential oils, terpenes and acetogenins (ACGs), which are typical of these plants. Chemically, ACGs are $\mathrm{C}_{35}-\mathrm{C}_{38}$ compounds of apparent polyketide origin that possess one or two tetrahydrofuran rings and a $\beta$-lactone (either saturated or unsaturated), and they usually contain aliphatic regions that are variously hydroxylated, acetoxylated, or ketonised. ${ }^{7-10}$ The chromatographic separation of hexane extracts of A. macroprophyllata seeds led to the isolation of the ACGs laherradurine, cherimoline-2, rolliniastatin-2 and isorolliniastatin-2, which correspond to $0.1 \%$ of the endosperm's weight. ${ }^{11-13}$ These ACGs are pharmacologically important because they are potent inhibitors of the mitochondrial NADH:ubiquinone-oxidoreductase (complex I of the respiratory chain). Laherradurine inhibits tumour cells but does not affect normal cells, and it could be used in the future as an antitumor drug. ${ }^{14-16}$ These secondary metabolites function in plant defence and occur in specific organelles and specific cells, thereby preventing toxicity to the plant itself and permitting site-specific defence. Staining with Kedde's reagent is a well-established technique used to identify ACGs in extracts from leaves, seeds and other plant structures by thin layer chromatography; it reacts with the $\beta$-unsaturated- $\gamma$-lactone moiety commonly found in annonaceous ACGs. ${ }^{8,17,18}$

The aim of this work was to histochemically determine the in situ localisation of ACGs in sections of $A$. macroprophyllata seeds using Kedde's reagent, as well as to analyse the co-localisation of ACGs with other storage molecules.
Correspondence: Guillermo Laguna Hernández, Facultad de Ciencias, Universidad Nacional Autónoma de México, Avenida Universidad 3000, Colonia Universidad Nacional Autónoma de México, C.U., Coyoacán 04510, México.

Tel. +52.55.56225431 - Fax: + +52.55.56224828.

E-mail: glagher@ciencias.unam.mx

Key words: Annona; Kedde's reagent; acetogenin histochemistry; storage reserves histochemistry; acetogenin idioblast.

Contributions: all authors had substantial contributions to the acquisition, analysis, or interpretation of data for the work.

Conflict of interest: the authors declare no conflict of interest.

Acknowledgments: the authors thank Dr. Patricia Rivas Manzano and Biol. Carlos Tonatiuh Chavira Ramírez for technical assistance with the cryostat sectioning in the Laboratory of Tissue and Reproductive Biology, Faculty of Sciences, National Autonomous University of Mexico.

Received for publication: 29 January 2015. Accepted for publication: 5 April 2015.

This work is licensed under a Creative Commons Attribution NonCommercial 3.0 License (CC BYNC 3.0).

(C) Copyright G. Laguna Hernández et al., 2015 Licensee PAGEPress, Italy

European Journal of Histochemistry 2015; 59:2502 doi:10.4081/ejh.2015.2502

\section{Materials and Methods}

\section{Plant materials}

A. macroprophyllata seeds were collected in San Lucas, Chiapas, Mexico. The herborised sample was collected in June 2013 and was deposited in the Eizi Matuda Herbarium of the Universidad de Ciencias y Artes de Chiapas, Tuxtla Gutiérrez, Chiapas, Mexico under reference voucher \#354.

\section{Germination conditions}

The seeds were germinated in Conviron environmental chambers that were maintained at $24-28^{\circ} \mathrm{C}$ with $12 \mathrm{~h}$ light/dark cycles and a relative humidity of approximately 65 $75 \%$. Light was delivered by cool white ultrahigh-output fluorescent lamps at an intensity of $500 \mathrm{~mW} \mathrm{~m}^{-2} \mathrm{~s}^{-1}$.

\section{Growth test}

A total of 50 uncoated seeds were rehydrated on a paper sheet under controlled temperature and light conditions. ${ }^{19}$ Consistent with previous results, ${ }^{20} 65 \%$ of the seeds germinated, and the seedlings were selected after 10 days of imbibi- 
tion, when the radicle was 1 or $2 \mathrm{~cm}$ in length and metabolism was fully established. The seeds were then cut in half at the midline and processed as illustrated in Figure 1.

\section{Seeds used for fresh sections}

Some of the seed halves were stored in water until sectioning on a cryostat. Others were stored in $70 \%$ alcohol, and others were fixed in FAA (10\% formaldehyde/50\% alcohol/5\% acetic acid/35\% water) for $72 \mathrm{~h}$ or in AGF $(1.5 \%$ acrolein $/ 3 \%$ glutaraldehyde $/ 1.5 \%$ formaldehyde in $0.1 \mathrm{M}$ sodium cacodylate buffer, $\mathrm{pH} 7.4$ ) (Electron Microscopy Sciences, Hatfield, PA, USA) for $12 \mathrm{~h}$. Then, the seed halves were washed with distilled water. Some halves were processed for paraffin embedding, ${ }^{21}$ and others remained in water until sectioning.

\section{Histochemistry on fresh sections}

The seeds that were stored in water, whether fixed or not, and the seeds that were stored in $70 \%$ alcohol were cut into $20-\mu \mathrm{m}$ cross sections using a Leica CM1510S cryostat at between -14 and $-18^{\circ} \mathrm{C}$. Once on slides, the fresh sections were washed with distilled water three times for $5 \mathrm{~min}$ per wash to eliminate the Tissue Tech gel. The excess water near the section was absorbed with filter paper, and then the appropriate reagent was added. Kedde's reagent ${ }^{8}$ (10\% dinitrobenzoic acid and $2 \mathrm{~N} \mathrm{KOH}$ in $\mathrm{MeOH}$ ) is specific for ACGs, and a positive reaction yields a pink/magenta color. Lugol's iodine solution ( $0.5 \mathrm{~g}$ iodine and $2.0 \mathrm{~g} \mathrm{KI}$ in $100 \mathrm{~mL}$ distilled water) yields a dark purple color when it reacts with starch. Sudan III $(0.1 \% \text { in } \mathrm{EtOH})^{18}$ yields a reddish orange color in the presence of fats. All analyses were performed at room temperature (approximately $23^{\circ} \mathrm{C}$ ). After the reagents were applied, the samples were immediately observed through a microscope for ten to thirty minutes and photographed.

\section{Histochemistry on paraffin sections}

The paraffin-embedded samples were cut into 8- $\mu \mathrm{m}$ sections using a Microm HM $340 \mathrm{E}$ microtome (Thermo Fisher Scientific, Inc., Waltham, MA, USA), deparaffinised, rehydrated, stained for 10 min with Kedde's reagent to visualise the ACGs, and observed under a microscope. Other sections were rehydrated in $70 \% \mathrm{EtOH}$ and stained with Naphthol Blue Black (1.0\% in 50\% EtOH) for protein analysis, and others were rehydrated in water, exposed to periodic acid (0.6\%) for $1 \mathrm{~min}$, and rinsed with distilled water. Then, Schiff reagent (Sigma-Aldrich 3952016; S. Louis, MO, USA) was added, incubated for 20 min and rinsed with distilled water. Then, the sample was dehydrated with xylene and mounted with resin. With this treatment, the polysaccharides stained a fuchsia color. Johansen's quadruple stain was added to sections that had been rehydrated in $70 \%$ EtOH. According to
Johansen, although the mixtures are rather complicated, the procedure is simple; differentiation is automatic, and little is left to personal judgment. ${ }^{21}$

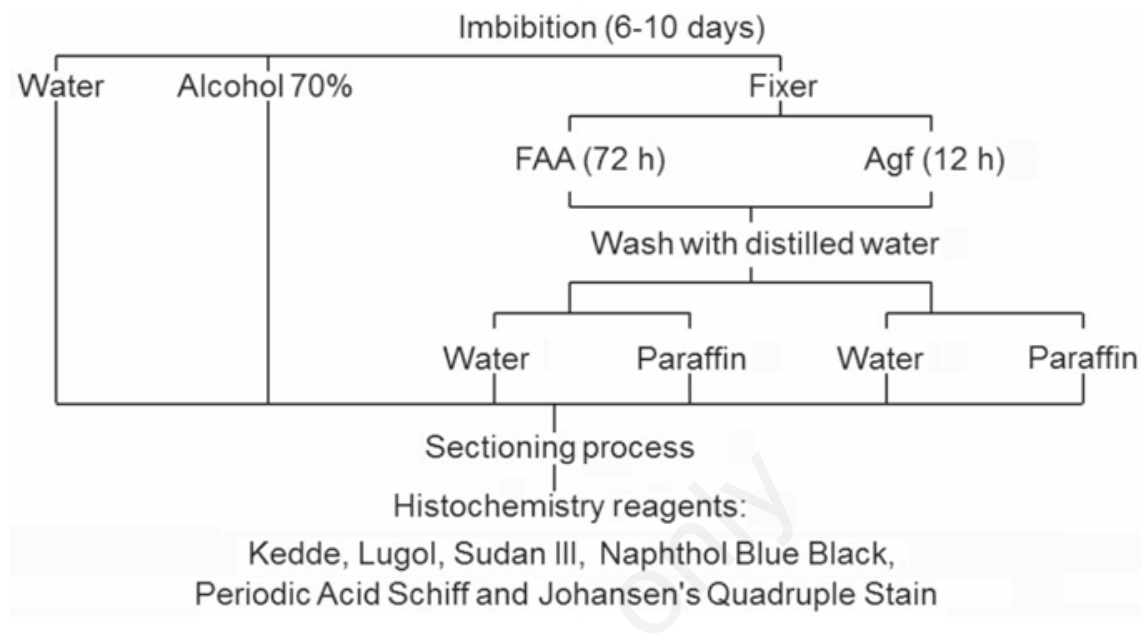

Figure 1. Methods flowchart.
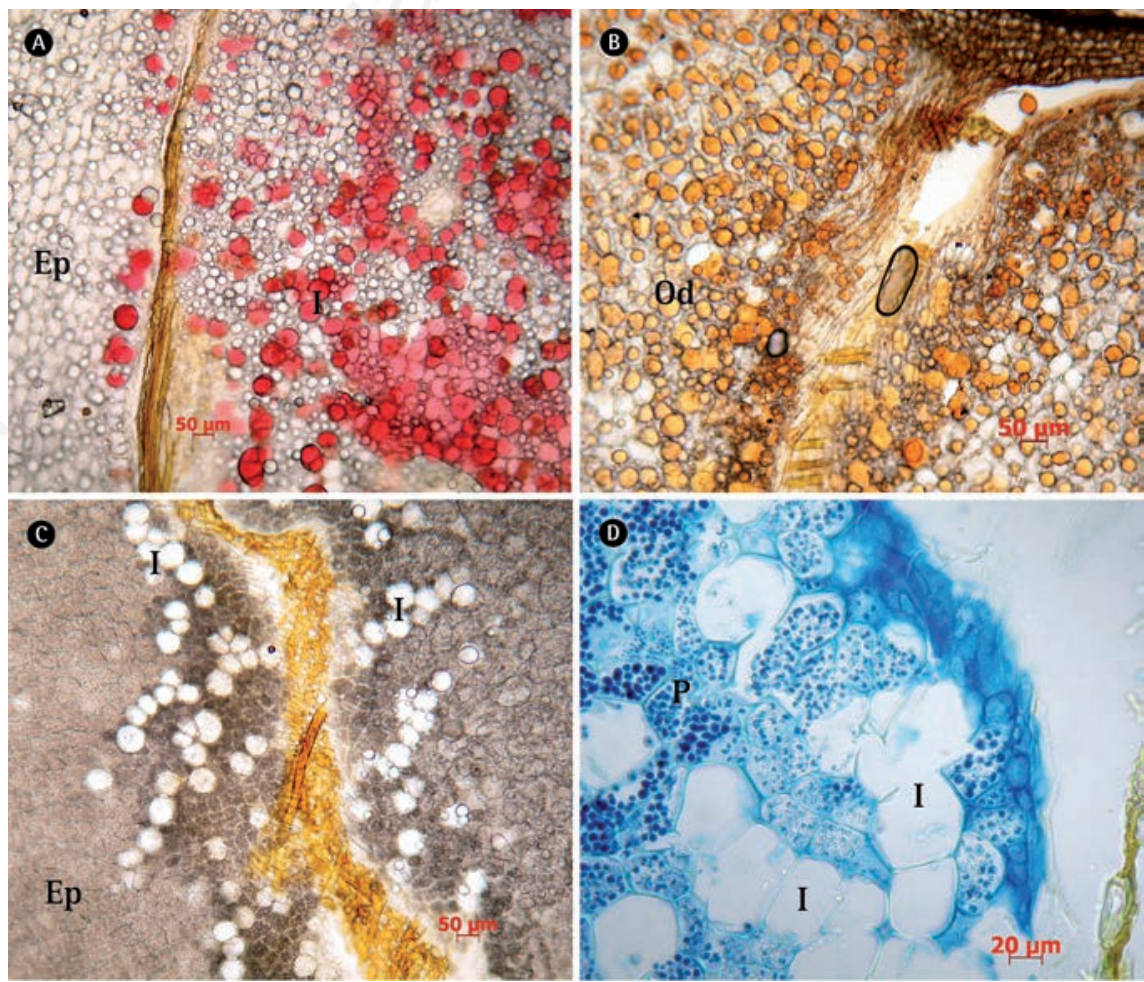

Figure 2. A) Kedde's reagent positively reacts with the acetogenins in the idioblasts of fresh, unfixed sections, yielding a pink/magenta color. B) Sudan III positively reacts with oil drops to yield a reddish orange color in fresh, unfixed sections. C) Kedde's reagent does not react with fresh sections fixed in FAA; the idioblasts appear empty. D) Naphthol Blue Black reagent stains the cell walls and proteoplasts of paraffin sections blue, and the idioblasts appear empty. Ep, endosperm parenchyma; I, idioblasts; Od, oil drops; P, proteoplasts. 


\section{Microphotography}

Photographs and idioblast measurements were taken with a Canon PowerShot A640 digital camera coupled to a Zeiss Axiostar Microscope with AxioVision software (Carl Zeiss Imaging Systems, Jena, Germany). Microscopic observations were made with APlan 10x/0.25 and A-Plan 40x/0.65 Ph2 objectives.

\section{Results and Discussion}

Positive reactions with Kedde's reagent were only observed in fresh sections that were either unfixed or had been fixed in AGF and preserved in water, and staining was found only in the large cells $(56 \times 38 \mu \mathrm{m})$ at the periphery of the endosperm next to the tegmen; these cells are idioblasts (Figure 2A). The lipid nature of the ACGs was confirmed by their positive reaction with Sudan III in both fresh sections and sections that had been fixed in AGF (Figure 2B). Therefore, we propose that histochemical staining is appropriate for detecting ACGs and that the large cells are idioblasts that store ACGs.

Due to the use of solvents such as ethanol and xylene, none of the sections that had been fixed in FAA, stored in 70\% alcohol, or embedded in paraffin showed staining in the idioblasts (Figure 2C). Naphthol Blue Black stained the cell walls blue, and the idioblast cytoplasm appeared secretory and lacked any special organelles; in the remaining endosperm cells, blue-stained proteoplasts were detected (Figure 2D) and might correspond to storage sites for albumin-type proteins, which have been reported to be stored in the endosperm of $A$. muricat ${ }^{5}$ and A. macroprophyllata $^{22}$ seeds. Johansen's quadruple stain turned these organelles purple (Figure $3 \mathrm{~A})$, confirming the presence of protein reserves.

The presence of oils, ${ }^{23}$ which act as reserve substances in the endosperm, was evident based on their reactivity with Sudan III (Figure 2B) and, indirectly, by the spaces observed in the cells in the paraffin-embedded material (Figure 3B). The material fixed in AGF, which had been preserved in water and sectioned on a cryostat, still contained ACGs in the idioblasts. The plastids were not stained by Schiff reagent (Figure 3C), demonstrating that they do not contain starch; their reaction with the crystal violet in Johansen's quadruple stain indirectly indicates that they contain proteins (Figure 2D).

Staining with Lugol's iodine (Figure 3D) did not indicate the presence of starch, but the reagent generated a golden brown color in
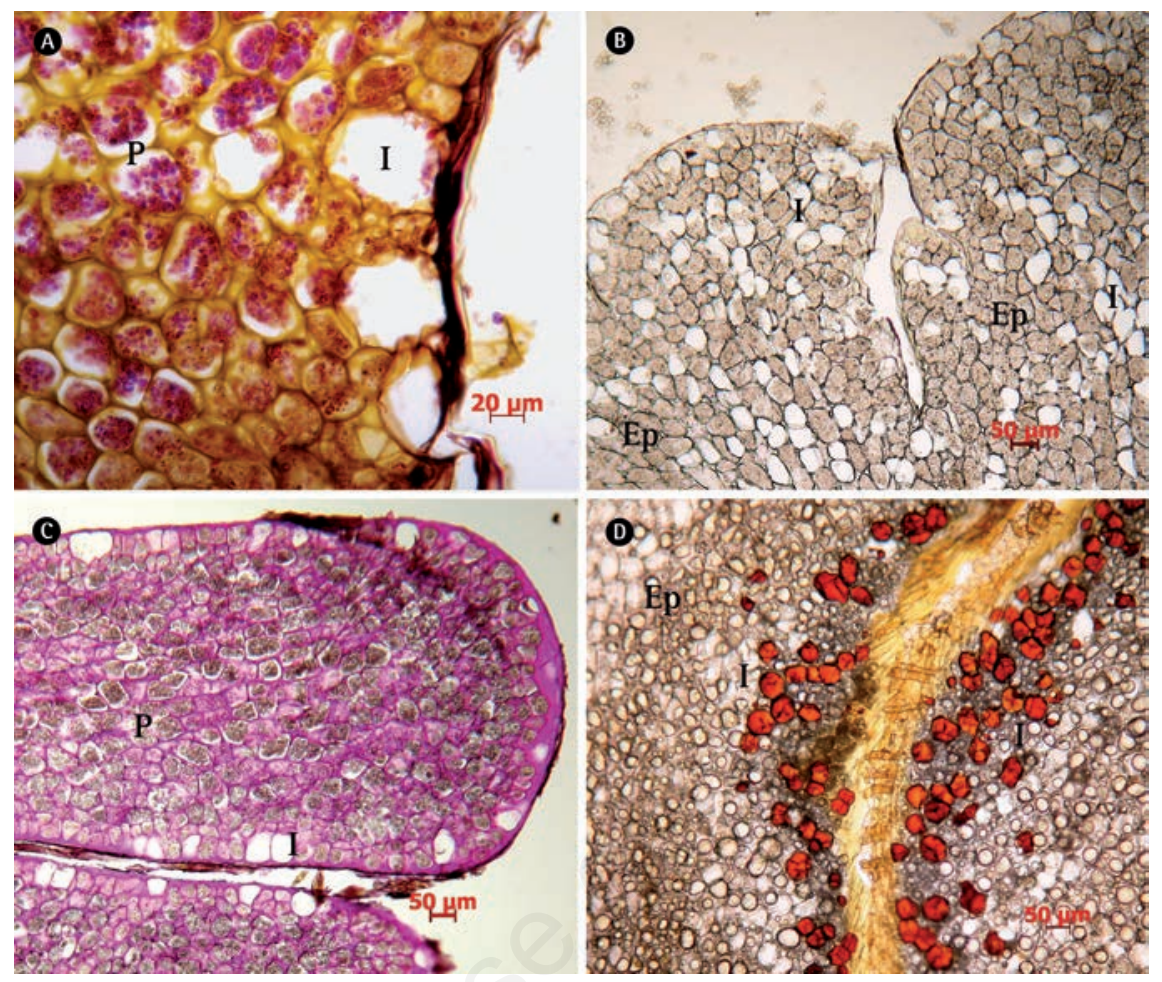

Figure 3. A) Johansen's quadruple stain used on a paraffin section stains the proteoplasts purple. B) Kedde's reagent used on a paraffin section does not react, and the idioblasts appear empty. C) Schiff reagent used on a paraffin section stains the cell walls purple, but the proteoplasts and idioblasts do not stain. D) Lugol's iodine used on a fresh, unfixed section results in golden brown-colored drops in the idioblasts. Ep, endosperm parenchyma; I, idioblasts; $P$, proteoplasts.

the idioblasts in the same place as the reaction with Kedde's reagent, indicating the presence of dextrins. ${ }^{5}$ However, the content appeared more like a drop-shaped liquid than the expected solid particles. This golden brown reaction product between the cytoplasmic content of the idioblasts and Lugol's iodine, which is similar in chemical composition to Wagner reagent, ${ }^{24}$ may indicate the presence of alkaloids. Therefore, this reaction deserves further histochemical study; the biosynthesis of liriodenine, an aporphinic alkaloid, begins during the early stages of development of seedlings of Annona macroprophyllata Syn A. diversifolia Saff. ${ }^{6}$

ACGs are bioactive compounds with cytotoxic properties in multiple cell lines, and they have antitumour, antiparasitic, antimalarial, insecticidal, antimicrobial, antifungal and antibacterial effects. ${ }^{15}$ In particular, the acetogenin laherradurin might act as an autoinducer or quorum-sensing signalling molecule that affects the expression of genes involved in biofilm formation in Pseudomonas plecoglossicida J26. ${ }^{18}$ Since ACGs are located in idioblasts that are found only in restricted areas in the periphery of the endosperm, despite the large amount of protein and oil reserves contained in the endosperm of mature seeds, ${ }^{25}$ ACGs may act as a barrier that protects seeds against insects and pathogens. In addition, the presence of alkaloids in the idioblasts might support this idea, because alkaloids are also strongly insect repellent and toxic to microorganisms. $^{17}$

Villamil et al. reported amyloid granules in A. muricata endosperm. ${ }^{5}$ However, in A. macroprophyllata, amyloids are not present because do not show blue or purple staining with Lugol's iodine in the endosperm cell walls, as reported by Kooiman ${ }^{2}$ for 25 species of Annonaceae. Some endosperm cells in $A$. macroprophyllata stain brown, which may correspond to dextrins. As described by Kooiman, ${ }^{2}$ the term amyloid refers to a group of polysaccharides with similar structures, particularly those reported by Schleiden in 1838 (in ${ }^{2}$ ) and by Vogel and Schleiden in 1839 (in ${ }^{2}$ ), who first used the term. Using Mitchell reagent, which has the same composition as Lugol's iodine, Kooiman detected cellulose and hemicellulose via blue staining in the presence of $75 \%$ sulphuric acid. Consistent with these ideas, we suggest that the term amyloid should no longer be used to refer to the group of compounds that can be detected with Schiff 
reagent, ${ }^{21}$ as the term is now used to refer to a beta-fibrillar protein of animal origin, the amyloid beta-protein. ${ }^{26}$

This new histochemical method for detecting ACGs in situ in seed sections using Kedde's reagent can test for the presence of these substances in developing tissue or mature organs. It can also differentiate between various substances in the same structures, as it occurred using Warner reagent to detect alkaloids in idioblasts. This work histochemically demonstrates the compartmentalisation of ACGs in the endosperm, suggesting that its aforementioned characteristics are part of a protective strategy that allows selective defence for the sexual propagation of the species.

\section{References}

1. Corner EJH. Annonaceous seed and its four integuments. New Phytol 1949;48: $332-64$.

2. Kooiman P. On the occurrence of amyloids in plant seeds. Acta Bot Neerl 1960;9:208-19.

3. Heijden E Van der, Bouman F. Studies in Annonaceae. Seed anatomy of the Annona group. Bot Jahrb Syst 1988;110:117-35.

4. Svoma E. Seed development and function in Artabotrys hexapetalus (Annonaceae). Plant Syst Evol 1997;207:205-23.

5. Villamil H, Corchuelo G, Valencia M. Morfología, anatomía de la semilla y composición química del endospermo de Annona muricata L. Agron Costar 1999;16: 19-23.

6. De la Cruz-Chacón I. González-Esquinca AR. Liriodenine alkaloid in Annona diversifolia during early development. Nat Prod Res 2012;26:42-9.

7. Ruprecht JK, Hui YH, McLaughlin JL. Annonaceous acetogenins: a rewiew. J Nat Prod 1990;53:237-78.

8. Cavé A, Cortes D, Figadère B, Laurens A, Pettit GR. Acetogenins from Annonaceae. In: W. Herz, G.W. Kirby, R.E.W. Moore, W.
Steglich and C.H. Tamm (eds.) Progress in the chemistry of organic natural products. Springer, Wien; 1997; pp. 81-288.

9. Alali FQ, Liu XX, McLaughlin JL. Annonaceus acetogenins: recent progress. J Nat Prod 1999;62:504-40.

10. Bermejo A, Figadère B, Zafra-Polo MC, Barrachina I, Estornell E, Cortes D. Acetogenins from Annonaceae: recent progress in isolation, synthesis and mechanisms of action. Nat Prod Rep 2005;22: 269-303.

11. De la Cruz-Chacón I. Acetogeninas Bioactivas de Annona diversifolia Safford. Tesis de Licenciatura. Instituto Tecnológico de Tuxtla Gutiérrez. Tuxtla Gutiérrez, Chiapas; 2001.

12. Schlie-Guzmán MA, García Carranca A, González-Esquinca AR. In vitro and in vivo antiproliferative activity of laherradurin and cherimolin-2 of Annona diversifolia Saff. Phytother Res 2009;23:1128-33.

13. Luna-Cazáres L, González-Esquinca AR. Susceptibility of bacteria and complete spheroplasts of Escherichia coli, Pseudomonas aeruginosa and Salmonella typhi to rolliniastatin-2. Nat Prod Res 2010;24:1139-45.

14. Zafra-Polo MC, Figadère B, Gallardo T, Tormo R J, Cortés D. Natural acetogenins from Annonaceae, sinthesis and mechanism of action. Phytochemistry 1998;48: 1087-117.

15. De Pedro N, Cautain B, Melguizo A, Cortes $\mathrm{D}$, Vicente F, Genilloud 0 , et al. Analysis of cytotoxic activity at short incubation times reveals profound differences among Annonaceus acetogenins, inhibitors of mitochondrial Complex I. J. Bioenerg. Biomembr 2013;45(1-2):145-152.

16. Cortes D, Moreno L, Párraga J, Galán A, Cabedo N. Nuevos fármacos inspirados en Annonaceas. Rev Bras Frutic 2014;36:22-31.

17. Cunha MM, Nascimento FC, SantosPimenta LP, Boaventura MAD, Salas CE, Lopes MTP. Screening of cytitoxic activity in hexanic and ethanolic extracts of
Rollinia laurifolia. Lat Am J Pharm 2009;28:234-40.

18. Parellada EA, Ferrero M, Cartagena E, Bardón A, Neske A. Laherradurin, a natural stressor, stimulates QS mechanism involved in biofilm formation of a PAHs degrading bacterium. Int Biodeter Biodegrad 2013;85:78-84.

19. Ministerio de Agricultura. Reglas internacionales para ensayos de semillas. Instituto Nacional de Semillas y plantas de Vivero. Dirección General de la Producción Agraria. Reimpreso por la SARH, México; 1976.

20. González-Esquinca AR, De la Cruz-Chacón I, Dominguez-Gutú LM, Latency and germination of Annona macroprophyllata Donn. Sm (Annonaceae): the importance of micropylar plug and seed position. Bot. Sci 2015 (In press).

21. Johansen DA. Plant microtechnique. McGraw-Hill Book Co., Inc., New York; 1940.

22. Ferreira G. Reguladores vegetais na superacao da dormencia, balanco hormonal e degradacao de reservas em sementes de Annona diversifolia SAFF. e A purpurea Moc. Sesse ex Dunal (Annonaceae). Thesis, UNESP Institute of Biosciences, Botucatu, Brazil; 2011.

23. Pérez-Amador MC, González-Esquinca A, García Argaez A, Bratoeff E, Labastida C. Oil composition and flavonoid profiles of the seeds of three Annona species. Phyton Int J Exp 1997;61:77-80.

24. Corsi G, Biasci D. Secretory structures and localization of alkaloids in Conium maculatum L. (Apiaceae). Ann Botany 1998;81: $157-62$.

25. De la Cruz-Chacón I. Alcaloides bencilisoquinolínicos y su relación órgano-específica durante las primeras fases del desarrollo de Annona diversifolia Safford. PhD Thesis, National Autonomous University of Mexico; 2012.

26. Kyle RA. 2001. Amyloidosis: a convoluted story. Brit J Haematol 2001;114:529-38. 